\title{
The Classroom as a Makerspace: Use of Tablets and Cutting Plotter to Create Pop-Up Cards in Educational Environments
}

\author{
https://doi.org/10.3991/ijet.v14i10.10284 \\ Alejandro Bonnet de León, Jose Luis Saorin, Jorge de la Torre-Cantero, \\ Cecile Meier ${ }^{(\varpi)}$, Eliseo García Marrero \\ University of La Laguna, Tenerife, Spain \\ cemeier@ull.edu.es
}

\begin{abstract}
In some classrooms the use of digital tablets for students is already standardized and is integrated into the teaching-learning process of the school. On the other hand, the use of cutting plotters is not common, although they are low-cost, easy to use and transportable devices. These machines are usually found in digital fabrication spaces such as Makerspaces, Fab labs, etc. However, it is interesting to introduce these technologies in traditional classrooms. This article describes an experience carried out at Colegio San Isidro, Los Salesianos de la Orotava, Tenerife in the 3rd year of secondary school in the subject of plastic, visual and audiovisual expression, in which an activity of design and creation of pop-up cards has been carried out. This activity is made in many subjects in order to develop creativity or to understand threedimensional concepts (mathematics, plastic, etc.). This activity involves cutting and folding paper that is usually done with scissors or cutter. It is proposed to digitalize this activity by means of digital tablets and portable cutting plotters. At the end of the activity, all the students were able to make their pop-up card using the proposed technologies and felt able to carry out the work autonomously.
\end{abstract}

Keywords-Makerspace, education, pop-up, cutting plotter, vectorization

\section{Introduction}

From 2013 it is already indicated that digital tablets will be technologies that will have an impact on education in the coming years. Digital tablets and mobile devices are used by $83 \%$ of children at the age of 14 [1]. One of the most extensive tablet studies "The iPad as a tool for education - a case study" [2] demonstrates the significant and very positive impact on students' teaching and learning. Digital tablets, due to their portability and autonomy, allow any classroom to be converted into a digital space and are positively accepted by actual students (digital natives) without any problem [3].

Digital manufacturing technologies include the process of creating, editing and managing digital files [4]. Until a few years ago, all these processes required special- 
ized training, usually in the fields of engineering and architecture. However, with the evolution of software and hardware, these technologies have become accessible, both economically and in terms of training, so that processes linked to digital manufacturing can be carried out easily [5]. Therefore, the incorporation of these technologies in educational environments is a viable option [6].

Within the different international reports on education there is a specific one on technologies that has become a reference: the "Horizon Report". In this report, specifically the one analyzing new technologies in secondary and high school, the creation of digital manufacturing laboratories (also known as Fablabs or Makerspaces) has been included since 2015 and is expected to be a reality for less than a year [7]. As the report also points out, its implementation in primary and secondary schools is already a reality in cases such as Frysklab, the creative workshop of the Fryslan municipal library (Holland), the Makerspace of the Sierra Vista Secondary School of La Puente, in California, or the Secondary School of Monticello, in Charlottesville, Virginia, providing workspaces for technological research with tangible benefits such as reduced absenteeism from school, improvement in subjects such as mathematics or interest in science or engineering careers, based on the use of digital manufacturing tools. In Spain, Galicia will implement next year the first Bachillerato STEMbach (of excellence in sciences and technologies) that include Maker spaces [8].

The learning of digital design and manufacturing is also beginning to be recognized in official bodies. For example, at a local level, the Department of Economy, Industry, Commerce and Knowledge of the Canary Islands Government, in July 2016, in its call for grants aimed at improving the digital skills of the population living in the Canary Islands, includes design, modelling and digital manufacturing among the three themes of the call [9]. As a result of this initiative, the Ministry of Education in the Canary Islands has created the program "STEAM for the promotion of scientific vocations and creativity". This program includes training activities, linked to design and digital manufacturing, aimed at secondary and high school education. Specifically, two Fab Labs have been created in 2018, one in the Teacher Training Centre in La Laguna and the other in Las Palmas de Gran Canaria, and the intention is to create another eight, spread over the seven islands. In addition, this program is supporting the creation of Makerspaces in secondary schools. To carry out educational projects, manufacturing machinery such as $3 \mathrm{D}$ printers and laser cutting machines are available in these laboratories [10]. They are equipped with tools used for the exportation of models to 3D printers or with tools which can calculate the tool path which will be engraved in a $\mathrm{CNC}$ machine in wood, metal, methacrylate or any other material, so as to obtain a physical and tangible object of the 3D model designed by the computer [11].

However, despite these advances, it is still difficult to have a digital manufacturing laboratory or maker classroom in the school itself [12]. Due to this, it is interesting to propose activities that introduce digital manufacturing in any space. In the educational environment, there are centers that have implemented 3D printers in the classroom and research into the scope that this digital manufacturing tool has on students [13]. Although the results are acceptable, the work times of 3D printers tend to exceed the time available in ordinary sessions during school hours. 
In this sense, manufacturing using cutting machines can be an alternative to avoid the problems of excessive time required by $3 \mathrm{D}$ printers. Although this manufacturing process is not exactly the same as $3 \mathrm{D}$ printing, it may be a more feasible option in terms of the time needed to make large pieces or a larger number of them.

The construction of parts using cutting machines (milling machine, laser cutting machine and cutting plotter) is much faster but there is not much history of its use in educational environments such as high school. This is mainly due to its high cost, noise or dangerousness. However, the technological advances are allowing to solve these inconveniences and therefore, you can begin to design automated manufacturing activities by cutting in traditional classrooms with these tools. This article discusses a low-cost digital design and manufacturing activity that uses free applications on mobile devices to facilitate ubiquitous learning and a low-cost portable cutting plotter that allows the experiences of digital manufacturing labs to be transferred to any educational space.

The proposed activity consists of the production of pop-up cards by students, using a cutting plotter and vector drawing applications for digital tablets. Pop-up cards are foldable cards that generate three-dimensional shapes when opened. A pilot test has been developed with 72 students from the 3rd year of Secondary school of the Colegio San Isidro, Salesianos in La Orotava, within the framework of the subject of plastic, visual and audiovisual expression, in which these technologies have been incorporated. The results in the experience show that the digital manufacture by cutting plotter and the vectorial design by means of applications in digital tablets are viable in secondary education and are valued in a positive way by the students.

\section{Background}

\subsection{Activities trimmed paper (kirigami) in school environments}

The creation of pop-up cards enters the field of kirigami. The term kirigami derives from the Japanese words KIRU (cut) and KAMI (paper). There are many forms of kirigami, but the most widespread is the one that folds a paper in half, cuts a shape and generates a three-dimensional piece when opened [14]. This technique is also known as pop-up $[15,16]$.

Like paper, it is estimated that Kirigami was born in China and was used in everyday life as festive decorations or as religious motifs, but some of these designs were also used as patterns to make decorations in fabrics and ceramics expressing moral principles, philosophies and aesthetic ideals [17]. The oldest example of this surviving activity is a symmetrical circle, found in Xinjiang, China, dating from the 11th century [18]. This was also initially a knowledge that was transmitted orally until, in 1721, the first published reference on folding and cutting paper appears in a Japanese book by Kan Chu Sen [19].

Kirigami has traditionally been used as a decorative or entertainment technique. However, it is also used in architectural design [20], applications of kirigami have been found in the creation of solid structures at the micro-scale and metamaterials 
with graphene [21]. Other researches produce kirigami nanocomposites as plasma electrodes that open up a wide range of technological solutions for electronic devices [22]. The elasticity of materials is also tested, for example in batteries, using Kirigami techniques [23]. Even artificial muscles are created by the Kirigami design [24].

In the educational context, paper is cut and folded as usual. Monteiro Kobayashi and Ueno Yamada [25] present the use of origami and kirigami in a course that aimed to use these techniques as a recreational and educational resource, while seeking to introduce cultural aspects of the art of folding and cutting paper. Other research aims to increase spatial visualization skills through origami, kirigami and origamic architecture [26]. It is also used to learn fractals (fig. 1) in mathematics [27], to improve creative skills [28], to encourage creative thinking [29], to teach micro electromechanical systems [30], etc.

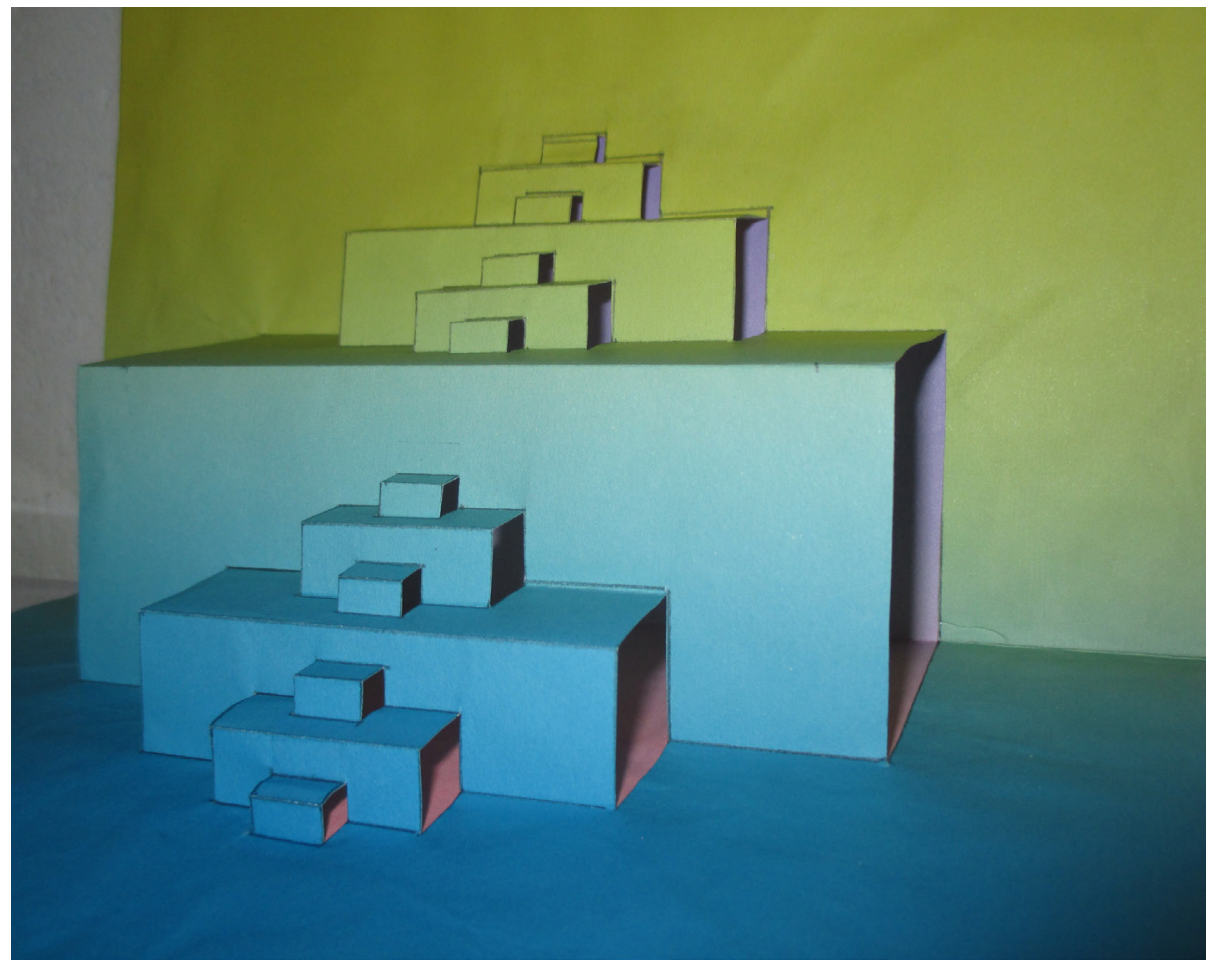

Fig. 1. Fractal Kirigami

Source: Wikimedia commons

In recent years there have been multiple applications and programs that create popups automatically using computer tools [31, 32, 33], however, in the activity described in this article the card designs were made without using automated composition processes, so that students would understand the principles of pop-up. For this purpose, vector drawing applications are used on mobile devices. Vector drawing is a format that is compatible with cutting machines. 


\subsection{Cutting machines in school environments}

Traditionally, colored papers, templates, folding bones and cutting tools such as scissors, cutters, knives, cutting shears, magnetic cutting bases, special knives, guillotines, etc. are used to make pop-up figures. Today there are digital cutting machines that can replace these tools. Within digital manufacturing there are two constructive forms: through the addition of material, known as additive manufacturing and the second through the suppression of the material or subtractive manufacturing. Each of the two has different shapes and variants, depending on the work being done. In educational environments, the best-known form of digital manufacturing are 3D printers. However, there are subtractive digital manufacturing techniques using cutting machines. Among the cutting devices are laser cutting machines, $\mathrm{CNC}$ milling machines or cutting plotters. These technologies have become cheaper in recent years, appearing economic options aimed at non-professional users that allow their integration in educational contexts [34].

With respect to the first of the cutting technologies, the milling machines, are machines that work in a mechanized way, cutting the material by means of the movement and rotation of a milling cutter. It has the capacity to cut, rough, file and sharpen materials of great thickness and hardness such as wood, metals, etc., depending on the specifications of each brand. Numerical control milling and cutting technology has also experienced a phenomenon similar to laser cutting tools with the emergence of affordable, personal fabrication oriented options. However, these machines have some drawbacks when it comes to introducing them in educational environments, such as the high level of noise and dust they produce as well as the need for specific training for handling digital files and selection of cutting parameters. In spite of this, didactic and hobby-oriented models are emerging that are increasingly reducing this type of inconvenience. Among these models we can find proposals such as "Carbide 3D", "Carvey", "MillRight CNC", "X-Carve" or "Stepcraft" (fig. 2a).

The second of these technologies, although there are "desktop" laser cutting machines aimed at personal manufacture, their use in educational environments involves certain dangers arising from the laser head and the emanation of gases depending on the material being cut, which require the use of an air filter. However, some of these machines are used in secondary schools in specific makerspaces or fab labs. These laboratories, with people trained in the use of digital manufacturing technologies have the ability to integrate laser cutting machines at prices ranging from 600 to $5000 \mathrm{eu}-$ ros, something unthinkable just two years ago. In this price range are the following tools "FABOOL Laser Mini" (fig. 2b), "Mr Beam", "Full Spectrum Laser Hobby Series" or "Glowforce".

Another digital manufacturing technology is the cutting plotter. This type of machine has a head with a blade that moves over the surface of the material to be cut or die-cut. On a professional level it is usually used in the graphic industry and the material most commonly used is vinyl, although there is the possibility of doing so with a wide variety of materials. For a price between 1000 and 2000 euros, you can buy a cutting plotter with professional characteristics. However, for about 250 euros, there are cutting plotters that can be purchased in paper shops oriented to the phenomenon 
of scrapbooking (personalization of albums by cut-outs). These machines, not much larger than a paper printer, are easy to operate and can cut a wide variety of materials such as paper, cardboard, cloth, eva rubber, etc. and are perfectly compatible with most computers and image files with which you usually work in school environments. Among these devices we can find models such as Cameo and Curio from the company Silhouette, the Cricut, the Stika series from the company Roland, or ScanNcut from Brother among others. Some of them are sold with a transport bag with wheels that allows you to move them very comfortably (fig. 3).

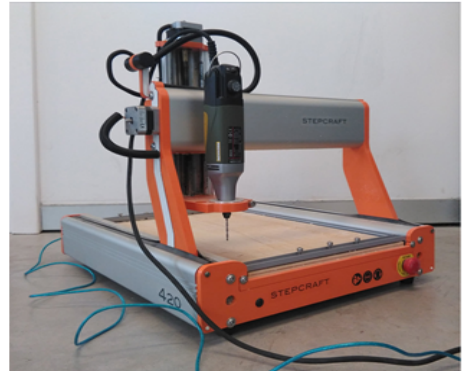

(a)

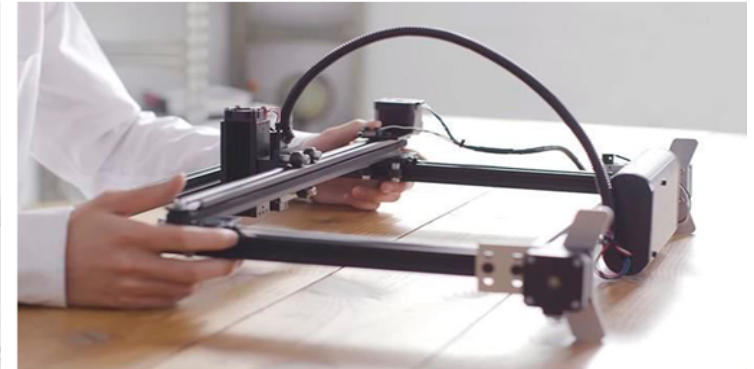

(b)

Fig. 2. (a): Hobby-oriented milling machine: Stepcraft 420, (b): Desktop laser cutting machine: FABOOL Laser Mini

Source: https://www.smartdiys.cc/products/fabool-laser-mini

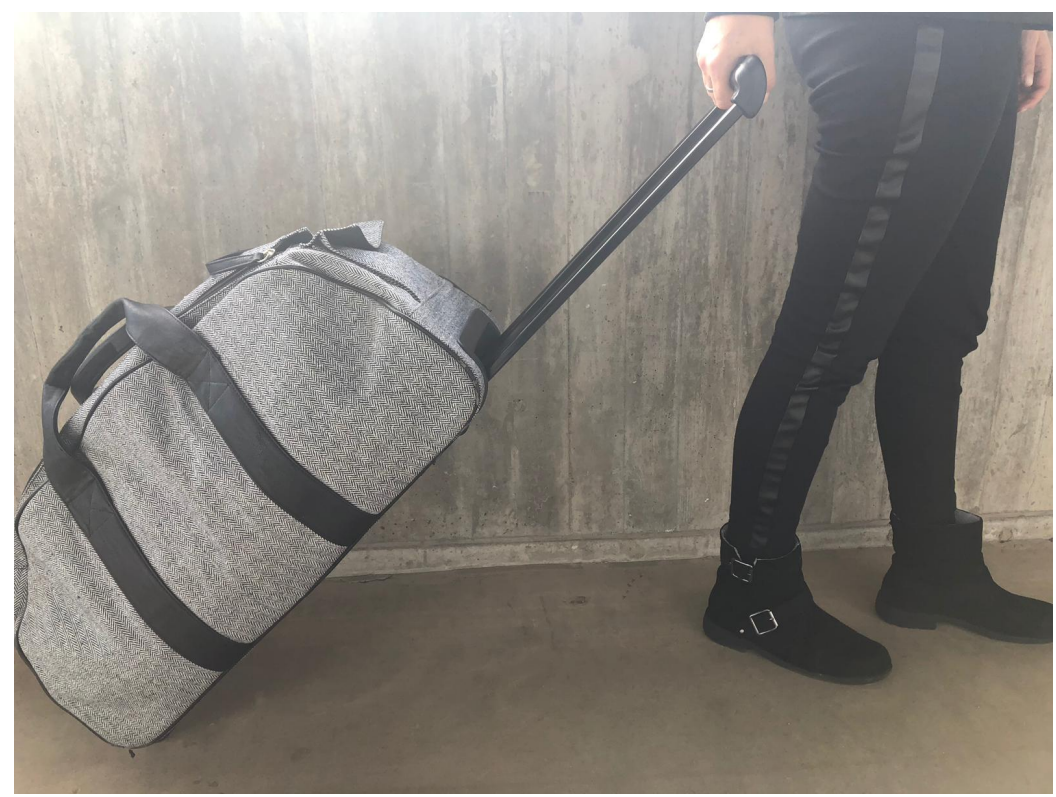

Fig. 3. Portable Cutting plotter 
In the field of education, tools are valued that are simple to operate, do not require a complex installation, can be transported easily, do not produce waste and are affordable. In this sense, as we have seen, the best alternative among cutting machines is the low-cost cutting plotter. This tool is useful for cutting elements of small and medium thickness, from paper, cardboard, eva foam, acetate, etc. It cuts at a higher speed than by hand, generates little noise, does not release traces of material in the form of toxic waste or fumes and is not dangerous to use. Taking into account these characteristics, it is postulated as a suitable tool for use in school environments. The cuts produced with the plotter are related to the same processes that can be carried out with a cutter or scissors, but the digital result is usually more precise and faster.

\subsection{Digital design of the pop-up cards}

To be able to cut with a cutting plotter, laser cutter or milling machine it is necessary to have a digital file that can be interpreted by the machine. These files are generally known as vector drawings. These are formed by geometric objects such as points, segments, polygons, arcs or lines. Each of them has mathematical properties of form, position, etc. that can be read by numerical control machines [35]. The usual vector graphics formats are svg (scalable vector graphic) or dxf (Drawing Exchange Format), so when exporting a file these extensions will be used. Some programs or applications do not allow export in these formats so it is necessary to use a program to change it. Currently there are several free online resources to perform this action, such as convertio, cloudconvert, aconvert, etc.

Vectorization is worked in many artistic disciplines such as design or illustration. There are a series of programs, applications, etc. that allow vector drawing. They are divided into computer programs, applications for devices such as tablets or mobiles and online programs that normally work on various devices. Some programs allow manual vectorization and others do it automatically from an image or photograph. The programs that are to download and install on computers such as Illustrator or Autocad are usually the most powerful to work, but are complicated to learn, require an installation and can involve a large cost.

Another option are online programs, which minimize some of the problems seen above. These programs do not require installation since they work online, and although they do not have all the functions of professional programs such as Illustrator, they allow a basic vectorization in a very simple and intuitive way. Among these online programs, we can highlight Gravit designer, Vecteezy Editor or Vectr. Being online, they require continuous connection to the Internet, but are a viable and free option, very interesting, especially in educational environments, where it is usually difficult to install a program without the permission of administrators. However, you usually need a computer room to work with these programs because on mobile devices they work with difficulty.

To work with mobile devices such as Smatphones or digital tablets there are applications such as Skedio, Vector Art Studio or Imaengine Vector that are free and downloadable. They allow to work the vectorization in an efficient way, being an 
interesting alternative to the online or computer programs, since they do not need a continuous connection to Internet and they are very suitable for beginners.

\section{$3 \quad$ Materials and Methods}

\subsection{Participants}

The activity has been carried out at Colegio San Isidro, Los Salesianos de la Orotava, Tenerife in 3rd year of scondary school in the subject of plastic and visual expression. A total of 72 students participated. These students completed a previous knowledge questionnaire to assess their notions about the technologies to be used and their knowledge about pop-up cards. The following data were extracted from this questionnaire:

- $87.50 \%$ of the participants had no knowledge of vector design

- $97.22 \%$ have never used a cutting plotter

- $79.17 \%$ do not know what a Popup card is

\subsection{Hardware and software}

This activity was performed with ipads and two vector drawing apps. Because the center distributes a tablet for each student, and its use is integrated into the learning and teaching process of the center, the realization of this practice was possible in a classroom without computer equipment.

Coloured cards were provided for the whole group. The software and hardware used for the pilot test was as follows: For the vector drawing the Adobe Draw application was used and the Imaengine Vector application for Ipad and Iphone, which allows the possibility of importing images in various image formats, such as jpg. and export in svg. Which is compatible with the cutting plotter. The main tool that interests us for the activity is the vector pen and this app has it, its operation is simple and functional. It allows to make straight lines and vectorized curves, making use of fingers or a specific stylus.

A low-cost portable Silhouette Cameo cutting plotter $(300 €)$ with its accessories and the free Silhouette Studio 4.1 Basic Edition were used as a digital tool to automate the cutting of cardboards (fig. 4). 


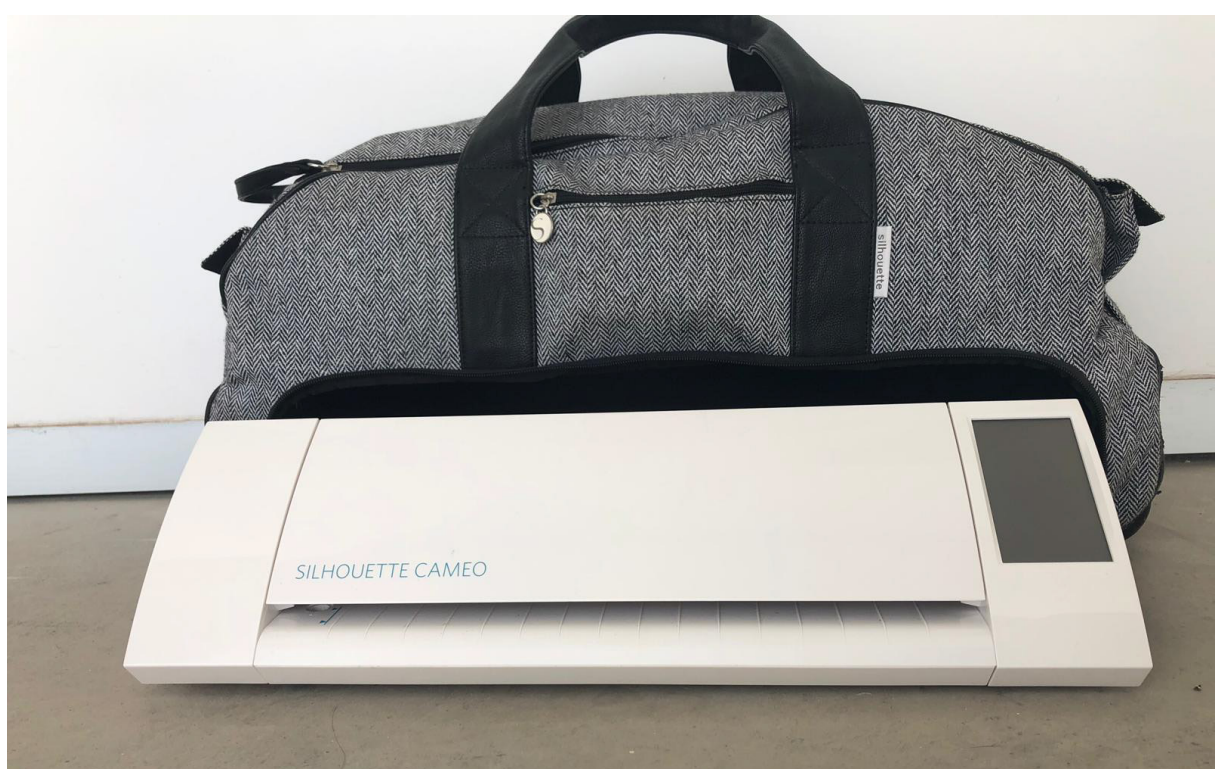

Fig. 4. Low-cost portable cutting plotte from Silhouette Cameo

\subsection{Experience carried out}

The experience consisted of generating pop-up cards related to the color learning situation, in the part of the representation of symbols with colors. To do this, each student chooses a color and then searches for an image of an object that represents that color.

The experience consisted in generating pop-up cards related to the chromatic circle and the symbols that represent the different colors using the new technologies. This activity is framed within the subject of Plastic, Visual and Audiovisual Education since it works with the contents of this subject according to the curriculum of the 3rd year of secondary education. Among the contents of this subject stands out the accomplishment of compositions, abstract or figurative, with different graphical techniques and with the use of the TIC when it is necessary, to express sensations by means of the use of the color, valuing the expressive capacity of these elements (Government of Canary Islands, 2018).

In order to carry out the activity, the image chosen by each student must be simplified. To do this, it is imported into the Adobe Draw application and modified to obtain a simple symbol. This symbol is saved and imported into the Imaegine Vector application where the pen tool is selected to automatically vectorize the image (fig. 5).

Once all the outline and details are done, the file is exported in .svg format. Next, we must convert the .svg file into a dxf format in order to be able to work with it in the cutting plotter. For this step we used the program online and free convertio vector https://convertio.co/es/vector-converter/. 

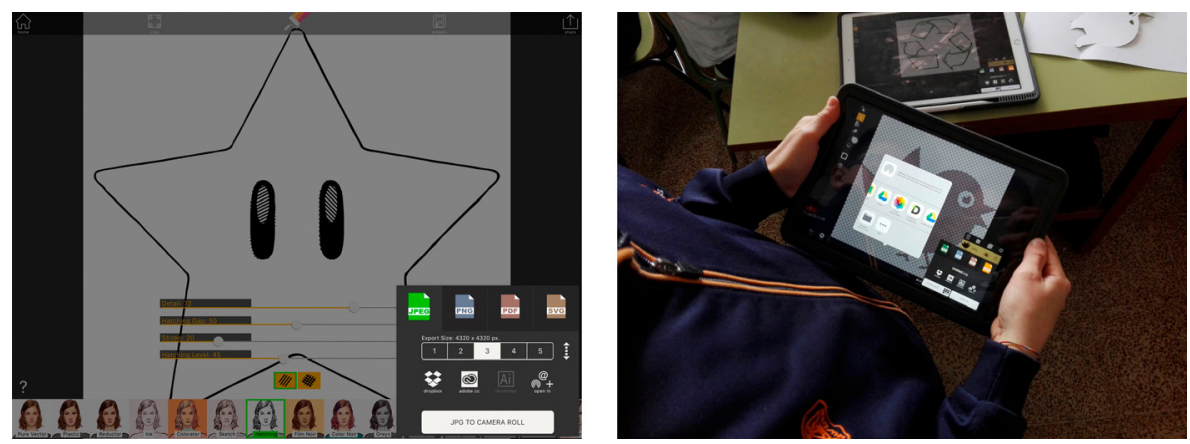

Fig. 5. Aplication Imaegine Vector for vectorize an image

Once we have the vector drawing in dxf format, we pass that file to the computer that is connected to the Silhouette cutting plotter. Import it into the Silhouette Studio program or drag the file into the program's interface. The program interface shows the mat located on a grid, which simulates the cutting space with that mat. When the image of the vector is located in the interface, the size is modified, the necessary arrangements are made, adding the flaps to turn the drawing into a pop-up and the lines are converted into dotted lines of those parts of the vector that we don't want the plotter to cut because that's where the folds will be made (fig 6a). These folds allow the third dimension to be taken out when folding the card.

Before cutting it is necessary to prepare the cutting settings of the Silhouette Studio 4.1 Basic Edition machine. In the same program they modify the necessary parameters of cut according to the material, in this case, it will be cardboard. This material appears in the predetermined cutting parameters and tells us at what height the blade should be. Then you just have to load the material into the plotter and send the file for cutting (fig 6b). To finish, the student makes the correct folds in the cut cardboard so that the three-dimensional shape of the pop-up stands out.

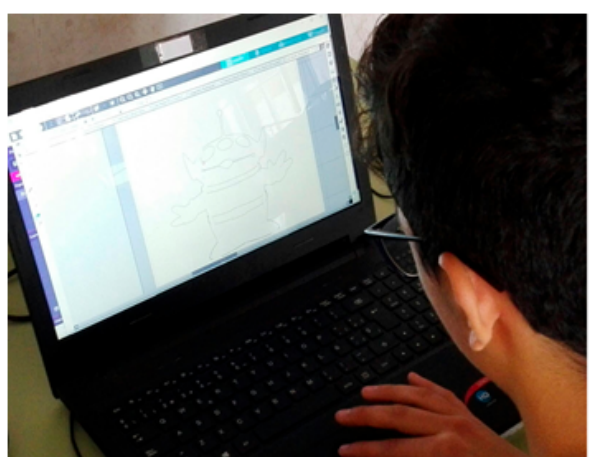

(a)

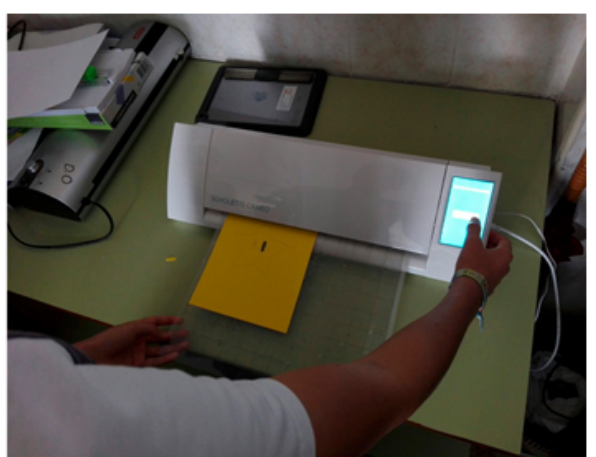

(b)

Fig. 6. (a): Student preparing the cutting settings of the Silhouette Studio 4.1 Basic Edition (b): Student loading the material into the plotter and send the file for cutting 
Finally, the pop-up cards are folded to achieve the third dimension (fig. 7).
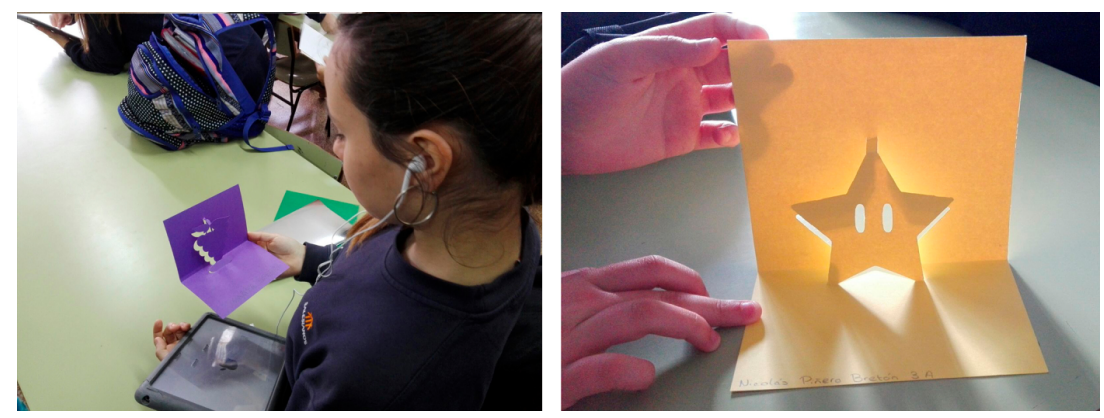

Fig. 7. Results obtained by the students

\subsection{Measuring instruments}

Two satisfaction questionnaires were used as a measuring instrument. A questionnaire prior to the activity to assess the initial idea that the students had about the activity and a subsequent questionnaire to assess the acceptance of the activity on the part of the student. Both questionnaires are valued according to the Likert scale, where there are five answer options: no agreement, little agreement, agreement, agreement enough, agreement enough and total agreement. In each of the questionnaires, and in order to see the effect that the activity has on the learning of the basic elements of this activity, they are asked if they know the vectorisation technologies, the cutting plotter and the pop-up cards. These questions are answered with yes or no.

The pre-activity Questionnaire questions are as follows:

- I believe that vectorization and cutting through machines makes sense within my student training

- I think creating 3D pop-up cards is difficult

- I prefer learning with traditional media over digital ones

- Digital materials are a good complement to my training

- I think I have the knowledge to vectorize

- The use of digital manufacturing technologies increases my motivation

The questions in the post-activity questionnaire are as follows:

- I found it easy to vectorize images

- I am satisfied with the result (pop-up card)

- I learned to use new digital tools

- I prefer to make pop-ups using digital tools rather than traditional ones

- I have obtained the necessary information to make pop-up on my own

- I would recommend the activity to others

- I think the cutter is very interesting for my own work

- I think that other subjects could use the cutting machines 


\section{$4 \quad$ Results}

Initial Questionnaire:

The following data on the basic elements of this activity were extracted from this questionnaire:

- $87.50 \%$ of the participants have no knowledge of vector design

- $97.22 \%$ have never used a cutting plotter

- $79.17 \%$ do not know what a Popup card is

Shows the results of the pre-activity satisfaction questionnaire:

Table 1. Results of the previous satisfaction questionnaire

\begin{tabular}{|l|l|c|}
\hline \multicolumn{1}{|c|}{ Question } & $\begin{array}{c}\text { Mean } \\
\text { (St.dev) }\end{array}$ \\
\hline 1 & I believe that vectorization and cutting through machines makes sense within my training. & $2.97(0.60)$ \\
\hline 2 & I think creating 3D pop-up cards is difficult. & $3.03(0.77)$ \\
\hline 3 & prefer traditional to digital learning & $2.53(1.19)$ \\
\hline 4 & Digital materials are a good complement to my training. & $3.79(0.92)$ \\
\hline 5 & I think I have the necessary knowledge to vectorize. & $2.32(0.95)$ \\
\hline 6 & The use of digital manufacturing technologies increases my motivation. & $3.78(0.86)$ \\
\hline
\end{tabular}

Post Questionnaire:

From this questionnaire, the following data were extracted on the basic elements subsequent to the carrying out of this activity:

- $100 \%$ of the participants have learned to carry out vector design. They know how to handle the cutting plotter and have learned the concept and how to create a popup card

Table 2 shows the results of the satisfaction questionnaire after the activity:

Table 2. Results of the post satisfaction questionnaire

\begin{tabular}{|l|l|l|}
\hline & \multicolumn{1}{|c|}{ Question } & \multicolumn{1}{|c|}{$\begin{array}{c}\text { Mean } \\
\text { (St.dev) }\end{array}$} \\
\hline 1 & I found it easy to vectorize images & $4.03(1.02)$ \\
\hline 2 & I am satisfied with the result obtained (pop-up card). & $4.55(0.83)$ \\
\hline 3 & I have learned to use new digital tools & $4.48(0.63)$ \\
\hline 4 & I prefer to make pop-ups using digital tools as opposed to traditional & $4.03(0.87)$ \\
\hline 5 & I have obtained the necessary information to perform pop-up on my own & $3.93(0.88)$ \\
\hline 6 & I would recommend the activity to others & $4.28(0.84)$ \\
\hline 7 & I think the cutting plotter is very interesting to make your own work & $4.38(0.82)$ \\
\hline 8 & I think other subjects could use the cutting machines & $4.31(0.60)$ \\
\hline
\end{tabular}




\section{Conclusion}

The results in experience show that digital manufacturing using cutting plotter and vector design using applications on mobile devices are feasible in secondary education without the need to create a Fab Lab (digital manufacturing laboratory) in the school. Therefore, it may be a good strategy to create some well-equipped regional fablabs and to complement each school with digital manufacturing activities with portable machines such as tablets and cutting plotters.

The plotter used that has a case with wheels is very comfortable to move. On the other hand, regarding the difficulty and reliability of this tool, we can say that the cutting plotter Silhouette Cameo 2 brand has worked properly without causing problems to students or teacher, because around 100 cuts made (between previous tests, exercise and errors), did not produce any failure of the machine itself. The problems detected were related to the additional materials, such as the mat and the wear of the blade. Therefore, both its price and its operation is optimal for work in schools.

The activity carried out within the framework of the subject of Plastic, Visual and Audiovisual Education works with the contents of this subject such as the making of compositions, abstract or figurative, with different graphic techniques and with the use of ICT when necessary, to express sensations through the use of color, valuing the expressive capacity of these elements. Therefore, it is an activity that fits perfectly in the subject and works several contents.

Before carrying out the activity, the students did not associate this type of exercise (vectorization and cutting) with the contents of the subject (2.97/5). However, once the activity was finished, the students not only stated that they had learned new digital tools $(4.48 / 5)$ but also that they would recommend cutting technologies for other subjects $(4.31 / 5)$. In addition, students reported that they were very satisfied with the result obtained (4.55/5).

When comparing the results of the initial questionnaire with the post-activity questionnaire on the basic elements following the completion of this activity, the following is obtained:

Although $87.50 \%$ of the participants had no knowledge of vector design, $100 \%$ learned to make vector drawings at the end of the activity. $97.22 \%$ of the students had never used a cutting plotter, however at the end of the activity $100 \%$ of the participants said that they had learned to use the cutting plotter. Although $79.17 \%$ of the participants did not know what a pop-up card was, $100 \%$ learned the concept and how to create a Popup card.

Regarding the use of digital technologies, it is observed that among the students the preference for learning with digital methods increased over traditional methods (2.53 in the initial questionnaire versus 4.03 in the later one). In addition, the students think that they have received the necessary knowledge to carry out the work autonomously (3.93 out of 5) and would also recommend the activity to other people (4.28 out of 5).

The work of the pop-up cards offers multiple options and themes. In this work, the form and the front fold for each one has been restricted, varying only the content or the image of the card. For future activities, the folds may vary as well as the type of cut. 


\section{Acknowledgement}

The financing granted by the ULL by the Ministry of Economy, Industry, Trade and Knowledge, $85 \%$ co-financed by the European Social Fund, is gratefully acknowledged.

\section{$7 \quad$ References}

[1] G. Cánovas, A. García de Pablo, A. Oliaga San Atilano y I. Aboy Ferrer, «Menores de Edad y Conectividad Móvil en España: Tablets y Smartphones,» Protegeles, España, 2014.

[2] P. Heinrich, The iPad as a tool for education, Kent: Naace, 2012.

[3] M. S. Rosli, N. S. Saleh, B. Aris, M. H. Ahmad y S. M. Salleh, «Ubiquitous Hub for Digital Natives,» International Journal of Emerging Technologies in Learning (iJET), vol. 11, no 2, pp. 29-34, 2016. https://doi.org/10.3991/ijet.v11i02.4993

[4] X. Wang, «Multimedia Teaching Platform for Urban Planning utilizing 3D Technology,» International Journal of Emerging Technologies in Learning (IJET), vol. 13, $\mathrm{n}^{\mathrm{o}} 4$, pp. 187199, 2018. https://doi.org/10.3991/ijet.v13i04.8259

[5] A. Bonnet de León, C. Meier, J. L. Saorín, J. de la Torre-Cantero y C. Carbonell, «Tecnologías de diseño y fabricación digital de bajo coste para el fomento de la competencia creativa,» Arte, Individuo y Sociedad, vol. 29, $\mathrm{n}^{\mathrm{o}}$ 1, pp. 85-100, 2017. https://doi.org/10.5209/aris.51886

[6] M. Bond, V. I. Marín, C. Dolch, S. Bedenlier y O. Zawacki-Richter, «Digital transformation in German higher education: student and teacher perceptions and usage of digital media,» International Journal of Educational Technology in Higher Education, pp. 1-20, 2018. https://doi.org/10.1186/s41239-018-0130-1

[7] A. Freeman, S. A. Becker y M. Cummins, «NMC/CoSN Horizon Report: K-12 Edition,» The New Media Consortium, United States, 2017.

[8] Europa Press, «Los centros gallegos contarán el curso que viene con un Bachillerato de excelencia en ciencias y tecnologías,» $30 \quad 11$ 2018. [En línea]. Available: https:/www.europapress.es/galicia/noticia-centros-gallegos-contaran-curso-vienebachillerato-excelencia-ciencias-tecnologias-20180611164944.html. https://doi.org/10.22201/cuaed.20074751e.2013.10.44234

[9] BOC, DISPOSICIONES GENERALES - Consejería de Economía, Industria, Comercio y Conocimiento, Canarias, 2016.

[10] Gobierno de Canarias, «Consejería de Educación y Universidades,» 3011 2018. [En línea]. Available: http:/www.gobiernodecanarias.org/educacion/web/programas-redeseducativas/programas-educativos/steam/.

[11] G. Licks, A. Teixeira y K. Luyten, «Smart Makerspace. A Web Platform Implementation,» International Journal of Emerging Technologies in Learning (iJET), vol. 13, $\mathrm{n}^{\mathrm{o}} 2$, pp. 140156, 2018. https://doi.org/10.3991/ijet.v13i02.7904

[12] H. Moorefield-Lang, «When makerspaces go mobile: Case studies of transportable maker locations,» Library Hi Tech, vol. 33, no 4, pp. 462-471, 2015. https://doi.org/10.1108/lht06-2015-0061

[13] J. de la Torre-Cantero, J. L. Saorín, C. Meier, D. Melián Díaz y M. D. D. Alemán, «Creación de réplicas de patrimonio escultórico mediante reconstrucción 3D e impresoras 3D de bajo coste para uso en entornos educativos,» Arte, Individuo y Sociedad, pp. 27(3), 427-444, 2015. https://doi.org/10.5209/rev aris.2015.v27.n3.45864 
[14] F. Temko, Kirigami: The Creative Art of Paper Cutting, New York: Platt \& Munk, 1962.

[15] D. A. Carter y J. Díaz, The elements of pop-up: A pop-up book for aspiring paper engineers, United States: Little Simon., 1999.

[16] H. M. Bromberg, «Pop-up card and method of making same». Washington Patente $5,450,680,1995$.

[17] R. Jablonski, The paper cut-out design book: a sourcebook for creating and adapting the heritage of American folk art, Polish wycinanki, Chinese hua yang, Japanese kirigami, German Scherenschnitte, and others, Owings Mills: Stemmer House., 1976.

[18] C. T. McCormick y K. K. White, Folklore: EL (Vol. 2), California: ABC-CLIO, 2011.

[19] K. C. Sen, Wakoku Chiyekurabe (Mathematical Contests), Japan: http://theory. lcs. mit. edu/ edemaine/foldcut/sen_book. html., 1721.

[20] S. Vyzoviti, Supersurfaces: Folding as a method of generating forms for architecture, products and fashion, Bis Pub, 2006.

[21] M. K. Blees, . A. W. Barnard, P. A. Rose, S. P. Roberts, K. L. McGill, P. Y. Huang, A. R. Ruyack, J. W. Kevek, B. Kobrin, D. A. Muller y P. L. McEuen, «Graphene kirigami,» Nature, $\mathrm{n}^{\circ}$ 524(7564), p. 204-207, 2015. https://doi.org/10.1038/nature14588

[22] T. C. Shyu, P. F. Damasceno, P. M. Dodd, A. Lamoureux, L. Xu, M. Shlian, M. Shtein, S. C. Glotzer y N. A. Kotov, «A kirigami approach to engineering elasticity in nanocomposites through patterned defects,» Nature Materials, vol. 14, p. 785-789, 2015. https://doi.org/10.1038/nmat4327

[23] M. Isobe y K. Okumura, «Initial rigid response and softening transition of highly stretchable kirigami sheet materials,» Scientific reports, $\mathrm{n}^{\circ}$ 6, 24758, 2016. https://doi.org/10.1038/srep24758

[24] S. Sareh y J. Rossiter, «Kirigami artificial muscles with complex biologically inspired morphologies,» Smart Materials and Structures, vol. 22(1), $\mathrm{n}^{\mathrm{o}}$ 014004, 2012. https://doi.org/10.1088/0964-1726/22/1/014004

[25] M. d. C. Monteiro Kobayashi y T. R. Ueno Yamada, «Origami e kirigami: arte e cultura como recurso lúdico e educativo,» Revista Ciência em Extensão, vol. 9, nº 3, pp. 148-158, 2013.

[26] V. C. P. Nogueira Valente y C. Yukari Ota, «The art of origami, kirigami and origamic architecture helping improve the spatial abilities,» de VIII World Congress on Communication and Arts, Salvador, Brasil, 2015.

[27] D. J. García Cuéllar, J. V. Flores Salazar y M. Martínez Miraval, «Génesis instrumental de la noción de fractal en docentes de matemáticas de nivel secundario,» de VIII CONGRESO IBEROAMERICANO DE EDUCACIÓN MATEMÁTICA. LIBRO DE ACTAS, Madrid, 2017. https://doi.org/10.4995/cifo17.2017.6778

[28] L. L. Castillo Cordova, Kirigami y habilidades creativas en estudiantes de las facultades de educación, Huancayo: Universidad nacional del centro de Perú, 2016. https://doi.org/10.26490/uncp.horizonteciencia.2012.2.38

[29] O. F. Romero Velasco y A. Tovar Cifuentes, Herramienta Didáctica Basada en Kirigami para Contribuir en el Desarrollo del Pensamiento Creativo, Implementada en Estudiantes de Grado Décimo de una Institución Educativa Distrital., Bogotá: Universidad distrital Francisco José de Caldas, 2018. https://doi.org/10.17227/20271034.13biografia239.251

[30] Y. C. Liang, «Applying kirigami models in teaching micro-electro-mechanical systems,» de 3rd Interdisciplinary Engineering Design Education Conference, Santa Clara, California, 2013. https://doi.org/10.1109/iedec.2013.6526765

[31] N. Harquail, M. Allen y E. Whiting, «Foldlings: a tool for interactive pop-up card design,» de Eurographics Workshop on Graphics for Digital Fabrication, Lisbon, 2016. 
[32] A. Glassner, «Interactive pop-up card design,» de IEEE Computer Graphics and Applications, 2002.

[33] S. Okamura y T. Igarashi, «An interface for assisting the design and production of pop-up card,» de International Symposium on Smart Graphics, Berlin, Heidelberg, 2009. https://doi.org/10.1007/978-3-642-02115-2 6

[34] J. L. Saorin, A. Bonnet de León, C. Meier y J. de la Torre-Cantero, «Retrato tridimensional mediante la utilización de tecnologías de fabricación digital de bajo coste en entornos educativos,» Arte, Individuo y Sociedad, pp. 295-309, 2018.

https://doi.org/10.5209/aris.56796

[35] S. Kalpakjian y S. R. Schmid, Manufactura, ingeniería y tecnología, México: Pearson Educación, 2002.

\section{Authors}

Alejandro Bonnet de León is $\mathrm{PhD}$ candidate in the department of education at the University of La Laguna, Calle Radio Aficionados, s/n, 38320 Santa Cruz de Tenerife, Spain. His research interest lie in the fields of creating learning activities using Makerspaces in secondary education.

Jose Luis Saorin is senior professor in the area of engineering graphics at University of La Laguna and funder of the FabLab in Tenerife, Calle Radio Aficionados, s/n, 38320 Santa Cruz de Tenerife, Spain. His research is about new interactive tecnologies and digital fabrication.

Jorge de la Torre-Cantero is Assistant Professor at University of La Laguna in the area of engineering graphics and founder of the FabLab Tenerife, Calle Radio Aficionados, s/n, 38320 Santa Cruz de Tenerife, Spain. He is specialised in advanced graphic tecnologies and digital fabrication.

Cecile Meier is an Assistant Professor at University of La Laguna at the department of fine arts, Calle Radio Aficionados, s/n, 38320 Santa Cruz de Tenerife, Spain. Her research is specialised in use of new tecnologies and digital fabrication in classroom.

Eiseo García Marrero is a Master student in the department of education at the University of La Laguna, Calle Radio Aficionados, s/n, 38320 Santa Cruz de Tenerife, Spain. His research is about the implementation of cutting machines in preuniversity levels of education.

Article submitted 2019-02-08. Resubmitted 2019-03-30. Final acceptance 2019-04-13. Final version published as submitted by the authors. 